\title{
MACHINE LEARNING APPROACHES FOR BURNED AREA IDENTIFICATION USING SENTINEL-2 IN CENTRAL KALIMANTAN
}

\author{
Anugrah Indah Lestari, ${ }^{1,2 *}$, Dyah Lalita Luhurkinanti ${ }^{1}$, Hajar Indah Fitriasari ${ }^{1}$, Ruki Harwahyu ${ }^{1}$, Riri Fitri Sari ${ }^{1}$ \\ ${ }^{1}$ Faculty of Engineering, Universitas Indonesia, Depok, Indonesia \\ ${ }^{2}$ Indonesian National Institute of Aeronautics and Space, Jakarta, Indonesia
}

Forest or land fire is a disaster that commonly occurred in Indonesia mainly in Kalimantan and Sumatera. Optical remote sensing satellite becomes a promising technology that can be utilized to identify the burned area in quick time for disaster management response. This study evaluated the use of supervised machine learning, such as Support Vector Machine (SVM), Random Forest (RF), and Deep Neural Network (DNN) to classify burned area in the Central Kalimantan province on June and August 2019 as pre-fire event and post-fire event using Sentinel-2 imageries. An imbalanced and a balanced dataset with varying hyper-parameter were used on those classifiers. Hotspot data derived from MODIS and Suomi NPP data are also used as training and testing dataset. Based on the study, the imbalanced dataset influences precision and recall values, as well as the accuracy of SVM and DNN classifiers, but not as much in RF. RF classifier outperforms SVM and DNN in terms of precision, recall, and accuracy for both a balanced dataset and an imbalanced dataset with the accuracy ranged from $98.2-99.3 \%$. The accuracy of SVM classifier is ranged from $94.7-98.1 \%$ for an imbalanced dataset and $90.4 \%-98.2 \%$ for a balanced dataset. Although the high accuracy is still can be achieved in DNN classifier, there is a changing accuracy from $98.5-98.8 \%$ in a balanced dataset to $95.5-95.7 \%$ in an imbalanced dataset. These findings imply that the high accuracy is still can be achieved by SVM, RF, and DNN classifiers with an imbalanced or a balanced dataset.

Key words: burned area, classification, deep neural network, machine learning, random forest, remote sensing satellite, support vector machine

\section{INTRODUCTION}

Forest or land fire is a disaster that occurs every year in Indonesia, mainly on Kalimantan and Sumatera [1], [2], [3]. In 2015, the burned area in Indonesia reached 2.6 million hectares in which $16 \%$ of them located in the Central Kalimantan. The overall economic impact loss reached USD 71 million according to the World Bank [4]. Also, the data from the Ministry of Environment and Forestry shows that Central Kalimantan becomes the largest burned area which is about 134 thousand hectares in the year 2019 [5]. Furthermore, the burned area gives many negative impacts includes health and social activities disruption, greenhouse gas emissions, and loss of flora and fauna diversity [6], [7]. With many negative impacts, the government and related institutions need to immediately take actions. However, to do that, they have to know the information about the burned area, such as the exact location and how large the impact is. Therefore, burned area information is needed for disaster management and impacts analysis [8].

Remote sensing satellite imagery is an alternative technology that can be utilized to acquire reliable information regarding the burned area [8]. Optical remote sensing satellite data on low to moderate spatial resolution has been widely used to identify burned area such as using MODIS sensor [2], [9], [10], [11] and Landsat [12], [13], [14]. Besides, high spatial resolution satellite data such as Sentinel-2 data is also promising to be used for burned area detection [15], [16], [17], [18] as it gives more burned area estimation due to the ability to identify small fires [19].

In these past years, with the rise of machine learning technology, the research on geospatial data using machine learning is also increasing. One of the application that is mostly performed using machine learning is land use and land cover classification with Deep Neural Network (DNN), Support Vector Machine (SVM), Ensemble Classifier using high spatial resolution imagery [20] and Random Forest (RF), k-Nearest Neighbor, and SVM using Sentinel-2 [21]. Those research implied that SVM and RF classifiers are more versatile to be used than deep learning for land use and land cover application since they were less sensitive to imbalanced data [22]. However, DNN classifier has beneficial for remote sensing application which has complex physical model [23]. For instance, increasing accuracy can be achieved using DNN classifier for land use and land cover application [24].

Some research has been done about the analysis of burned area with machine learning methods. In the case of burned area research, classifier such as RF, SVM, and neural network, is respectively investigated using PROBA-V reflectance imagery [25] and MODIS data [11], [26], [27], [28]. Those research implied that RF classifier is the most optimum to be implemented and neural network classifier needs parameter tuning so that it is 
more complex than RF and SVM. Some strategy such as validation-loss should also be done to overcome imbalanced dataset in neural network classifier [11] so that the use of DNN classifier for burned area identification is still needed further research.

This study is aimed to acquire and evaluate the burned area information model from SVM, RF, and DNN classifier using Sentinel-2 imagery. The SVM and RF classifiers was chosen since they are simple methods that commonly works well in image classification. Although deep learning is a promising technology in image analysis, it is still need to be researched comprehensively in case of the effectiveness. Therefore, the evaluation of those methods is needed by comparing those classifier.The physical parameters used are post-fire Normalized Burn Ratio $\left(\mathrm{NBR}_{\text {post-fire }}\right)$ and difference NBR between pre-fire and post-fire ( $\triangle N B R)$. Thus, NBR is one of the most significant parameters for burned area discrimination [29], [30]. The differences in the dataset used will also be a consideration for evaluation.

\section{MATERIALS AND METHODS}

\section{Study area and data}

Since Central Kalimantan is one of the areas that mostly affected by the forest and land fire in 2019 [5], this area, as seen in Figure 1, is chosen as the study area of this study.

Sentinel-2 imagery is chosen as it has high temporal res- olution [31] to minimize cloud cover issue. In this study, satellite imageries with the acquisition times in June and August 2019 were used as the dataset. Sentinel-2 consists of spectral bands as shown in Table 1 in which Narrow Near-Infrared (B8A) and Short-wave Infrared (B12) bands were used to acquire Normalized Burn Ratio.

Table 1:Sentinel-2 Spectral Bands [31]

\begin{tabular}{|c|c|c|}
\hline & Spectral band & $\begin{array}{c}\text { Spatial resolution } \\
(\mathbf{m})\end{array}$ \\
\hline B1 & Coastal aerosol & 60 \\
\hline B2 & Blue & 10 \\
\hline B3 & Green & 10 \\
\hline B4 & Red & 10 \\
\hline B5 & Vegetation red edge 1 & 20 \\
\hline B6 & Vegetation red edge 2 & 20 \\
\hline B7 & Vegetation red edge 3 & 20 \\
\hline B8 & NIR & 10 \\
\hline B8A & Narrow NIR & 20 \\
\hline B9 & Water vapour & 60 \\
\hline B10 & SWIR/Cirrus & 60 \\
\hline B11 & SWIR 1 & 20 \\
\hline B12 & SWIR 2 & 20 \\
\hline
\end{tabular}

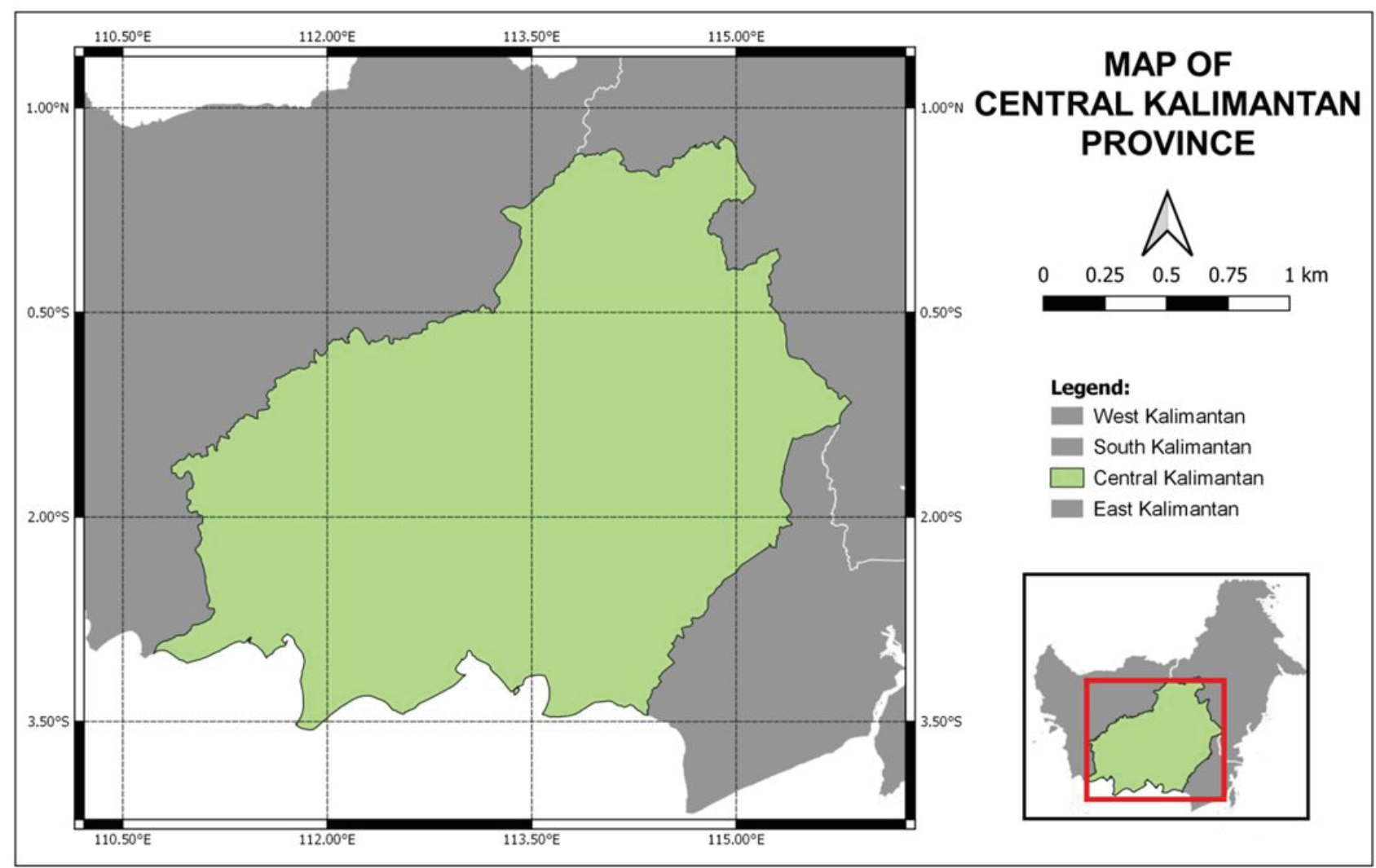

Figure 1: Study area in Central Kalimantan province 


\section{Methods}

Figure 2 illustrates the used methodology of this study. It covers the processing of remote sensing imagery which are cloud masking, mosaicking, feature extraction, algorithm training, parameter tuning, classification with each respective machine learning method. Furthermore, the model evaluation includes accuracy and error assessment was also done. Sentinel-2 imageries were acquired from Google Earth Engine, while the hotspot data that are from MODIS and Suomi NPP was derived from the Indonesian National Institute of Aeronautics and Space.

In the processing stage, an atmospheric correction was done to the Sentinel-2 data and clipped into the study area. All tasks in the processing stage were done using Google Earth Engine API in Python.

Features that are used in this study as a physical parameter to classify burned area are pre-fire Normalized Difference Burned Ratio (NBR $\left.{ }_{\text {pre-fire }}\right)$, post-fire Normalized Burned Ratio $\left(\mathrm{NBR}_{\text {post-fire }}\right)$ and $\Delta$ Normalized Burned Ratio $(\triangle N B R)$ with the formula in the Equation (1) and (2).

$N B R=(N I R-S W I R) /(N I R+S W I R)$

$\triangle N B R=N B R_{\text {pre-fire }}-N B R_{\text {post-fire }}$

which NIR is Near Infra-red Band and SWIR is Shortwave Infra-red Band.

\section{Training and testing dataset}

In this study, the dataset consists of two class namely burned and unburned pixels based on Sentinel-2 imagery derived from Google Earh Engine. $\triangle$ NBR categorization of burned severity from United States Geological Survey (USGS), shown in Table 2 and NBR post-fire $_{\text {values }}$ were used to label between burned and unburned pixels. Besides, hotspot data were also used as training samples. Combinations of the presence of hotspot in medium or high confidential levels and impressive features on a certain location are classified as burned area, whereas hotspot data with unimpressive features are classified as unburned area. This study used two different datasets.

Table 2: $\triangle N B R$ burned severity categories from USGS [32]

\begin{tabular}{|c|c|}
\hline $\boldsymbol{\Delta}$ NBR (scaled by 1000) & Category \\
\hline$<-250$ & High post-fire regrowth \\
\hline-250 to -100 & Low post-fire regrowth \\
\hline-100 to 100 & Unburned \\
\hline 100 to 270 & Low-severity burn \\
\hline 270 to 440 & $\begin{array}{c}\text { Moderate-low severity } \\
\text { burn }\end{array}$ \\
\hline 440 to 660 & $\begin{array}{c}\text { Moderate-high severity } \\
\text { burn }\end{array}$ \\
\hline$>660$ & High-severity burn \\
\hline
\end{tabular}

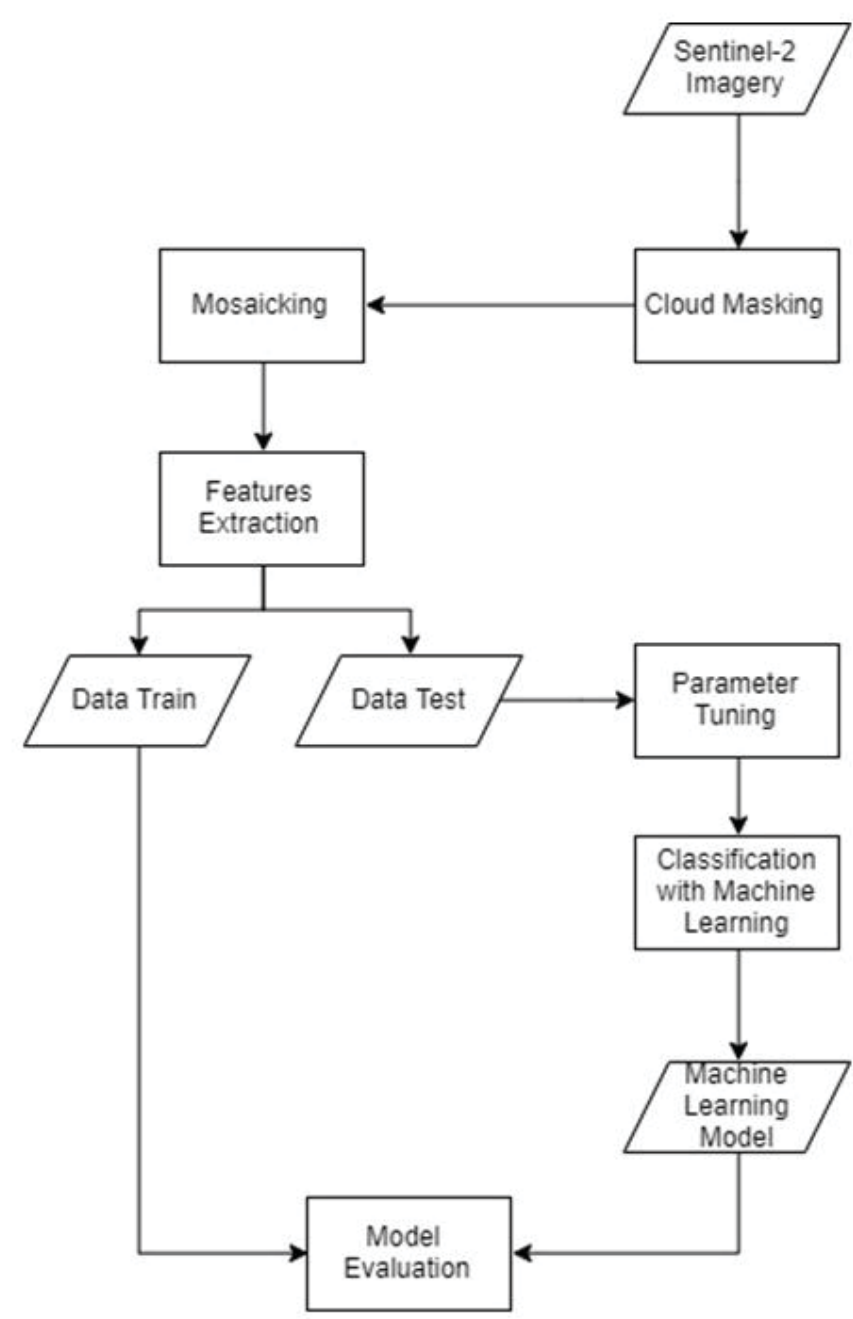

Figure 2: Research workflow

The first is the dataset with comparison is 75:25 between burned and unburned pixels respectively as imbalanced dataset and secondly is 50:50 between burned and unburned pixels respectively as a balanced dataset. The dataset was split into train data and test data.

\section{Implementation of classifier}

The model classification was developed using Python programming language. "Tensor Flow" framework was used to conduct DNN classifier, whereas the SVM and RF classifiers were performed using the "scikit-learn" module. Parameter tuning was performed in Support Vector Machine (SVM), Random Forest (RF), and Deep Neural Network (DNN) algorithm.

SVM is one of supervised machine learning methods, commonly used for classification and regression. Some hyper-parameter that can be tuned in the implementation of the SVM algorithm, such as a kernel, regularization parameter or also called cost $(C)$, and gamma $(\gamma)$. The parameter $y$ determines the influence of a single training data on the algorithm and $\mathrm{C}$ determine a misclassification size of training data [27]. A high value of $C$ tends to choose small margin and results in small error tolerance. Polynomial kernels and the radial basis function (RBF) 
kernel are commonly used for remote sensing application [33]. In this study, five values of $C(1,10,25,50$, and $100)$, and five values of $\gamma(0.0001 ; 0.02 ; 0.25 ; 0.1$; and 1) were tested.

Random Forest (RF) is one of the ensemble methods for classification or regression that consists of many decision trees. It has a hyper-parameter such as the number of trees. The average probability which is calculated by all trees determines the final classification [27]. In a random forest, the number of trees is the hyper-parameter that have to be set. In this study, the various number of trees were investigated namely 5, 10, and 20.

Deep Neural Network (DNN) consists of four main components namely input layer, neurons, hidden layer, and output layer. The number of hidden layers influences the model performance, but there is no fixed rule for determining it [20]. In this study, the number of hidden layers was varied. The rectified linear unit was used as an activation. Dropout was also used to prevent over-fitting. The data were trained with the fixed epoch of 50 .

\section{RESULTS AND DISCUSSION}

\section{SVM classifier}

Table 3 and Table 4 shows the root mean square error (RMSE) of SVM classifier for an imbalanced and a balanced dataset with a variation of $C$ value and $y$ value. The result shows that the lowest error produced by the high value of $C$ and the low value of $y$ in an imbalanced dataset. For instance, in this case, the C value of 100 and the $y$ value of 0.0001 generate the lowest RMSE. In case of a balanced dataset, there are significant changes in RMSE when the value of $y$ is high. In general, both an imbalanced and balanced data results in the lowest RMSE for the high value of $\mathrm{C}$ and the low value of $\gamma$.

Figure 3 and Figure 4 show the accuracy between $C$ and $\gamma$ values on SVM classifier with an imbalanced dataset and balanced dataset. The accuracy for an imbalanced and balanced dataset is ranging from $94.7 \%-98.1 \%$ for an imbalanced dataset and $90.4 \%$ - $98.2 \%$ for a balanced dataset. The result implies that the proportion of dataset for burned and unburned area pixels give impact for the accuracy although still can achieve high accuracy for both imbalanced and balanced dataset.

Table 3: The relationship between RMSE and hyper-parameters ( $C$ and $y$ ) of the SVM classifier with an imbalanced dataset

\begin{tabular}{|c|c|c|c|c|c|c|}
\hline \multirow{4}{*}{ C } & $\mathbf{1 0 0}$ & 0.019 & 0.027 & 0.029 & 0.038 & 0.049 \\
\cline { 2 - 7 } & $\mathbf{5 0}$ & 0.027 & 0.046 & 0.036 & 0.053 & 0.045 \\
\cline { 2 - 7 } & $\mathbf{2 5}$ & 0.033 & 0.036 & 0.031 & 0.034 & 0.038 \\
\cline { 2 - 7 } & $\mathbf{1 0}$ & 0.023 & 0.029 & 0.034 & 0.046 & 0.034 \\
\hline $\mathbf{1}$ & 0.025 & 0.036 & 0.042 & 0.038 & 0.445 \\
\hline & $\mathbf{0 . 0 0 0 1}$ & $\mathbf{0 . 0 2}$ & $\mathbf{0 . 2 5}$ & $\mathbf{0 . 1}$ & 1 \\
\cline { 2 - 7 } & \multicolumn{6}{|c}{ gamma (y) } \\
\hline
\end{tabular}

Table 4: The relationship between RMSE and hyper-parameters ( $C$ and $\gamma$ ) of the SVM classifier with a balanced dataset

\begin{tabular}{|c|c|c|c|c|c|c|}
\hline \multirow{5}{*}{ C } & 100 & 0.027 & 0.030 & 0.066 & 0.081 & 0.096 \\
\hline & 50 & 0.018 & 0.033 & 0.060 & 0.048 & 0.084 \\
\hline & 25 & 0.018 & 0.045 & 0.042 & 0.042 & 0.093 \\
\hline & 10 & 0.024 & 0.033 & 0.072 & 0.048 & 0.060 \\
\hline & 1 & 0.027 & 0.051 & 0.066 & 0.051 & 0.072 \\
\hline & & 0.0001 & 0.02 & 0.25 & 0.1 & 1 \\
\hline & & & & & & \\
\hline
\end{tabular}

Table 5: The relationship between accuracy and hyper-parameters ( $\mathrm{C}$ and $\mathrm{y}$ ) of the SVM classifier with an imbalanced dataset (in percent \%)

\begin{tabular}{|c|c|c|c|c|c|c|}
\hline \multirow{5}{*}{ C } & 100 & 98.1 & 97.0 & 97.0 & 96.2 & 95.1 \\
\hline & 50 & 97.2 & 95.3 & 96.4 & 94.7 & 95.5 \\
\hline & 25 & 96.6 & 96.4 & 96.8 & 96.6 & 96.2 \\
\hline & 10 & 97.7 & 97.0 & 96.6 & 95.3 & 96.6 \\
\hline & 1 & 97.5 & 96.4 & 95.7 & 96.2 & 95.5 \\
\hline & & 0.0001 & 0.02 & 0.25 & 0.1 & 1 \\
\hline & & & & ma & & \\
\hline
\end{tabular}

Table 6: The relationship between accuracy and hyper-parameters ( $C$ and $y$ ) of the SVM classifier with a balanced dataset (in percent \%)

\begin{tabular}{|c|c|c|c|c|c|c|}
\hline \multirow{5}{*}{ C } & 100 & 97.3 & 96.9 & 93.4 & 91.9 & 90.4 \\
\hline & 50 & 98.2 & 96.7 & 93.9 & 95.2 & 91.6 \\
\hline & 25 & 98.2 & 95.5 & 95.8 & 95.8 & 90.7 \\
\hline & 10 & 97.6 & 96.7 & 92.8 & 95.2 & 93.9 \\
\hline & 1 & 97.3 & 94.9 & 93.4 & 94.9 & 92.8 \\
\hline & & 0.0001 & 0.02 & 0.25 & 0.1 & 1 \\
\hline & & & & nma ( & & \\
\hline
\end{tabular}

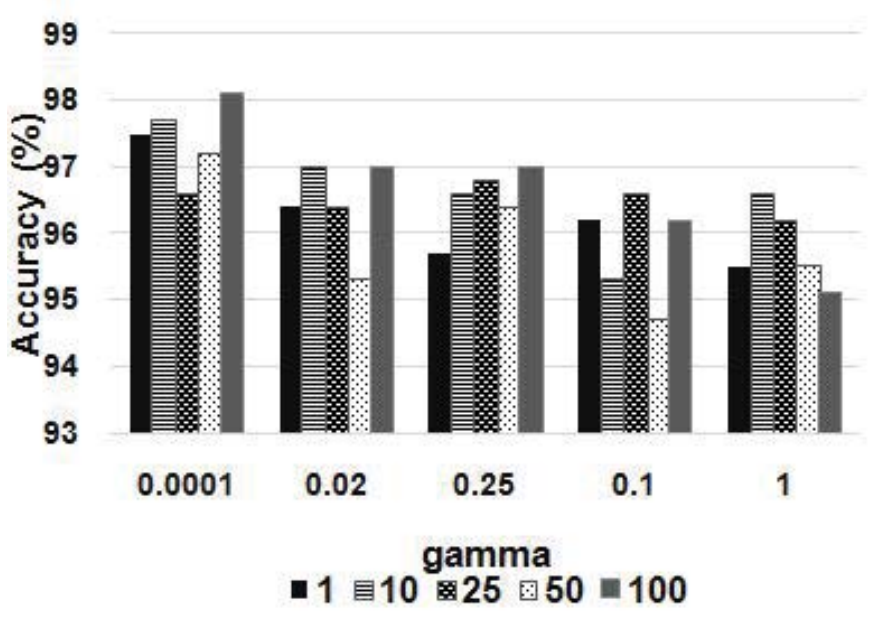

Figure 3: Accuracy on certain $C$ and y values on SVM classifier with an imbalanced dataset 


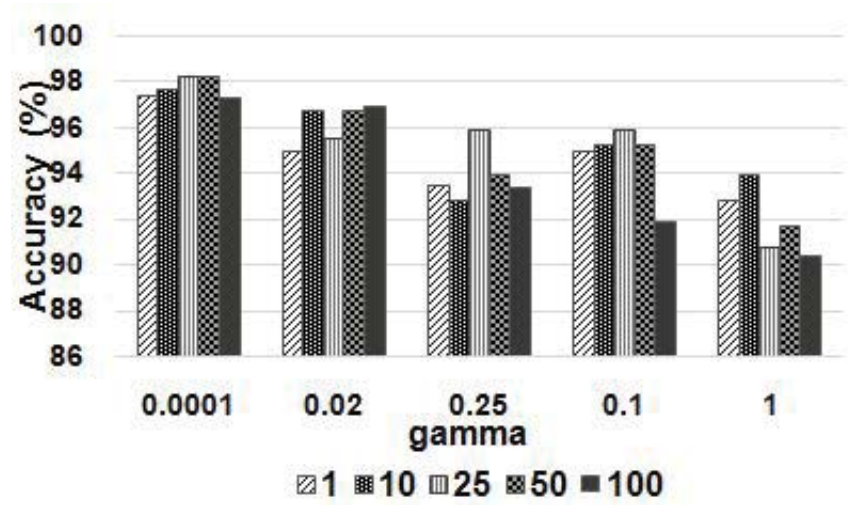

Figure 4: Accuracy on certain C and $y$ values on SVM classifier with a balanced dataset

The precision and recall values were also investigated since they are an effective measurement for the success of prediction [11]. In the case of an imbalanced dataset, the ratio between burned area and unburned area pixels was 75:25. Table 7 and Table 11 show that there are no significant changes in precision and recall values for burned area pixel, which are ranging from 0.95-0.99 with various $\mathrm{C}$ and $\gamma$ value. In contrast, there are significant changes in the recall values but still with high precision for unburned area pixels in an imbalanced dataset. However, the precision values obtained for unburned area pixels are relatively smaller than burned area pixels which are ranging from 0.88-0.96 as shown in Table 9. It shows that the SVM classifier is slightly affected by the imbalanced dataset.

In the case of a balanced dataset, the ratio between burned area and unburned area pixels was modified to 50:50. Table 8 and Table 13 show that burned area precision and unburned area recall values for a balanced dataset are relatively smaller than the imbalanced dataset when the gamma value was increased (ranging from $0.83-1$ ) with various $C$ and $y$ value but still with high precision for burned area pixels. In contrast, there are no significant changes in unburned area precision and burned area recall (ranging from 0.96-1).

Table 7: The relationship between burned area precision and hyper-parameters ( $C$ and $y$ ) of the SVM classifier with an imbalanced dataset

\begin{tabular}{|c|c|c|c|c|c|c|}
\hline \multirow{3}{*}{$\mathrm{C}$} & $\mathbf{1 0 0}$ & 0.99 & 0.98 & 0.97 & 0.97 & 0.95 \\
\cline { 2 - 7 } & $\mathbf{5 0}$ & 0.98 & 0.98 & 0.96 & 0.95 & 0.96 \\
\cline { 2 - 7 } & $\mathbf{2 5}$ & 0.99 & 0.98 & 0.97 & 0.98 & 0.97 \\
\cline { 2 - 7 } & $\mathbf{1 0}$ & 0.99 & 0.98 & 0.98 & 0.96 & 0.97 \\
\hline $\mathbf{1}$ & 0.99 & 0.98 & 0.96 & 0.97 & 0.96 \\
\hline \multirow{3}{*}{} & $\mathbf{0 . 0 0 0 1}$ & $\mathbf{0 . 0 2}$ & $\mathbf{0 . 2 5}$ & $\mathbf{0 . 1}$ & $\mathbf{1}$ \\
\cline { 2 - 6 } & \multicolumn{6}{|c|}{ gamma (v) } \\
\hline
\end{tabular}

Table 8: The relationship between burned area precision and hyper-parameters ( $C$ and $y$ ) of the SVM classifier with a balanced dataset

\begin{tabular}{|c|c|c|c|c|c|c|}
\hline \multirow{4}{*}{ C } & $\mathbf{1 0 0}$ & 0.95 & 0.96 & 0.88 & 0.87 & 0.83 \\
\cline { 2 - 7 } & $\mathbf{5 0}$ & 1 & 0.94 & 0.90 & 0.91 & 0.85 \\
\cline { 2 - 7 } & $\mathbf{2 5}$ & 0.97 & 0.96 & 0.93 & 0.94 & 0.83 \\
\cline { 2 - 7 } & $\mathbf{1 0}$ & 0.98 & 0.96 & 0.86 & 0.91 & 0.89 \\
\hline $\mathbf{1}$ & 0.95 & 0.91 & 0.89 & 0.91 & 0.88 \\
\hline & $\mathbf{0 . 0 0 0 1}$ & $\mathbf{0 . 0 2}$ & $\mathbf{0 . 2 5}$ & $\mathbf{0 . 1}$ & $\mathbf{1}$ \\
\cline { 2 - 7 } & \multicolumn{6}{|c|}{ gamma (v) } \\
\hline
\end{tabular}

Table 9: The relationship between unburned area precision and hyper-parameters ( $C$ and $y$ ) of the SVM classifier with an imbalanced dataset

\begin{tabular}{|c|c|c|c|c|c|c|}
\hline \multirow{5}{*}{ C } & 100 & 0.94 & 0.96 & 0.96 & 0.95 & 0.94 \\
\hline & 50 & 0.94 & 0.96 & 0.98 & 0.92 & 0.92 \\
\hline & 25 & 0.89 & 0.88 & 0.97 & 0.91 & 0.96 \\
\hline & 10 & 0.90 & 0.94 & 0.92 & 0.92 & 0.96 \\
\hline & 1 & 0.90 & 0.91 & 0.95 & 0.94 & 0.94 \\
\hline & & 0.0001 & 0.02 & 0.25 & 0.1 & 1 \\
\hline & & & & ma & & \\
\hline
\end{tabular}

Table 10: The relationship between unburned area precision and hyper-parameters ( $C$ and $y$ ) of the SVM classifier with a balanced dataset

\begin{tabular}{|c|c|c|c|c|c|c|}
\hline \multirow{3}{*}{$\mathrm{C}$} & $\mathbf{1 0 0}$ & 0.99 & 0.99 & 1 & 0.99 & 1 \\
\cline { 2 - 7 } & $\mathbf{5 0}$ & 0.96 & 0.99 & 1 & 1 & 1 \\
\cline { 2 - 7 } & $\mathbf{2 5}$ & 0.99 & 0.96 & 1 & 0.98 & 1 \\
\cline { 2 - 7 } & $\mathbf{1 0}$ & 0.97 & 0.98 & 1 & 1 & 1 \\
\hline $\mathbf{1}$ & 1 & 0.99 & 1 & 1 & 1 \\
\hline & 0.0001 & 0.02 & 0.25 & $\mathbf{0 . 1}$ & 1 \\
\cline { 2 - 6 } & \multicolumn{5}{|c|}{ gamma (y) } \\
\hline
\end{tabular}

Table 11: The relationship between burned area recall and hyper-parameters ( $C$ and $\gamma$ ) of the SVM classifier with an imbalanced dataset

\begin{tabular}{|c|c|c|c|c|c|c|}
\hline \multirow{4}{*}{ C } & $\mathbf{1 0 0}$ & 0.98 & 0.99 & 0.99 & 0.99 & 0.98 \\
\cline { 2 - 7 } & $\mathbf{5 0}$ & 0.98 & 0.99 & 0.99 & 0.98 & 0.98 \\
\cline { 2 - 7 } & $\mathbf{2 5}$ & 0.96 & 0.98 & 0.99 & 0.98 & 0.99 \\
\cline { 2 - 7 } & $\mathbf{1 0}$ & 0.97 & 0.98 & 0.98 & 0.98 & 0.99 \\
\hline $\mathbf{1}$ & 0.97 & 0.98 & 0.99 & 0.98 & 0.99 \\
\hline & $\mathbf{6 . 0 0 0 1}$ & $\mathbf{0 . 0 2}$ & $\mathbf{0 . 2 5}$ & $\mathbf{0 . 1}$ & $\mathbf{1}$ \\
\cline { 2 - 7 } & \multicolumn{6}{|c}{ gamma (v) } \\
\hline
\end{tabular}


Table 12: The relationship between burned area recall and hyper-parameters ( $C$ and $y$ ) of the SVM classifier with a balanced dataset

\begin{tabular}{|c|c|c|c|c|c|c|}
\hline \multirow{4}{*}{ C } & $\mathbf{1 0 0}$ & 0.99 & 0.99 & 1 & 0.99 & 1 \\
\cline { 2 - 7 } & $\mathbf{5 0}$ & 0.97 & 0.99 & 1 & 1 & 1 \\
\cline { 2 - 7 } & $\mathbf{2 5}$ & 0.99 & 0.96 & 1 & 0.98 & 1 \\
\cline { 2 - 7 } & $\mathbf{1 0}$ & 0.97 & 0.98 & 1 & 1 & 1 \\
\hline $\mathbf{1}$ & 1 & 0.99 & 1 & 1 & 1 \\
\hline \multirow{6}{*}{} & 0.0001 & 0.02 & 0.25 & 0.1 & 1 \\
\cline { 2 - 6 } & \multicolumn{6}{|c|}{ gamma (v) } \\
\hline
\end{tabular}

Table 13: The relationship between unburned area recall and hyper-parameters ( $C$ and $y$ ) of the SVM classifier with an imbalanced dataset

\begin{tabular}{|c|c|c|c|c|c|c|}
\hline \multirow{5}{*}{ C } & 100 & 0.98 & 0.92 & 0.88 & 0.87 & 0.84 \\
\hline & 50 & 0.93 & 0.92 & 0.85 & 0.84 & 0.85 \\
\hline & 25 & 0.97 & 0.93 & 0.89 & 0.83 & 0.88 \\
\hline & 10 & 0.98 & 0.92 & 0.90 & 0.84 & 0.88 \\
\hline & 1 & 0.98 & 0.90 & 0.82 & 0.89 & 0.84 \\
\hline & & 0.0001 & 0.02 & 0.25 & 0.1 & 1 \\
\hline & & \multicolumn{5}{|c|}{ gamma (Y) } \\
\hline
\end{tabular}

\section{RF classifier}

Figure 5 depicts the accuracy derived from an imbalanced and a balanced dataset with a various number of tree. The accuracy is ranging from $98.7-99.1 \%$ for an imbalanced dataset and 98.2 - $99.3 \%$ for a balanced dataset. It implies that high accuracy can be obtained for both an imbalanced and a balanced dataset. Supporting Maxwell et al. [22] on remote sensing data studies which explicitly concluded that accuracy is not determined by the number of tree, this study also finds that accuracy is not affected by the number of trees.

Table 15 and Table 16 shows the RMSE, precision, and recall values of RF classifier for an imbalanced and a balanced dataset respectively with a various number of tree. The RMSE for an imbalanced and a balanced dataset is ranging from $0.103-0.113$ and $0.077-0.134$
Table 14: The relationship between unburned area recall and hyper-parameters ( $C$ and $\gamma$ ) of the SVM classifier with a balanced dataset

\begin{tabular}{|c|c|c|c|c|c|c|}
\hline \multirow{5}{*}{ C } & 100 & 0.95 & 0.95 & 0.87 & 0.84 & 0.82 \\
\hline & 50 & 1 & 0.94 & 0.87 & 0.90 & 0.84 \\
\hline & 25 & 0.97 & 0.96 & 0.91 & 0.98 & 0.82 \\
\hline & 10 & 0.98 & 0.96 & 0.87 & 0.91 & 0.88 \\
\hline & 1 & 0.95 & 0.91 & 0.86 & 0.90 & 0.85 \\
\hline & & 0.0001 & 0.02 & 0.25 & 0.1 & 1 \\
\hline & & & & ma & & \\
\hline
\end{tabular}

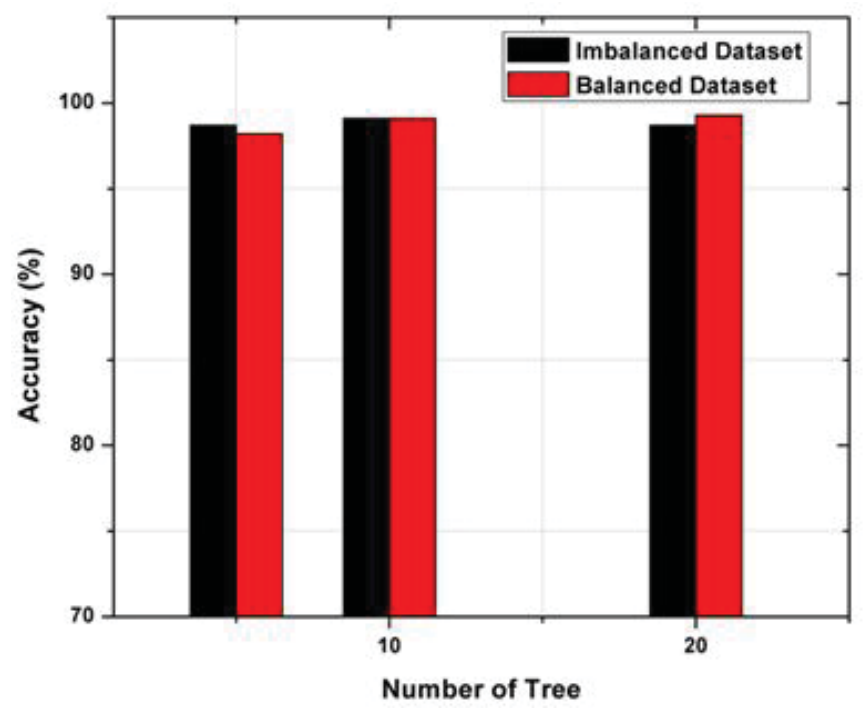

Figure 5: Accuracy between an imbalanced and a balanced dataset on RF classifier with varying number of tree

respectively. Regarding precision and recall values of the burned and unburned area in an imbalanced and a balanced dataset, the result shows that the precision and recall values from a various number of trees are relatively stable (ranging from 0.96-0.99) both for the burned area and unburned area pixel. It means that RF classifier is not affected by an imbalanced dataset since recall values of the unburned area still give high value and high precision. High recall and precision values mean that a large number of testing data have been predicted and results in a correct label.

Table 15: The relationship among number of tree and accuracy, RMSE, precision, as well as recall of RF classifier with an imbalanced dataset

\begin{tabular}{|c|c|c|c|c|c|c|}
\hline Number of tree & Accuracy & RMSE & $\begin{array}{c}\text { Precision of } \\
\text { burned area }\end{array}$ & $\begin{array}{c}\text { Recall of } \\
\text { burned area }\end{array}$ & $\begin{array}{c}\text { Precision of } \\
\text { unburned area }\end{array}$ & $\begin{array}{c}\text { Recall of unburned } \\
\text { area }\end{array}$ \\
\hline $\mathbf{5}$ & 98.7 & 0.103 & 0.99 & 0.99 & 0.96 & 0.98 \\
\hline $\mathbf{1 0}$ & 99.1 & 0.092 & 0.99 & 0.99 & 0.98 & 0.98 \\
\hline $\mathbf{2 0}$ & 98.7 & 0.113 & 0.99 & 0.99 & 0.96 & 0.98 \\
\hline
\end{tabular}


Table 16: The relationship among number of tree and accuracy, RMSE, precision, as well as recall of RF classifier with a balanced dataset

\begin{tabular}{|c|c|c|c|c|c|c|}
\hline Number of Tree & Accuracy & RMSE & $\begin{array}{c}\text { Precision of } \\
\text { Burned Area }\end{array}$ & $\begin{array}{c}\text { Recall of } \\
\text { Burned Area }\end{array}$ & $\begin{array}{c}\text { Precision of Un- } \\
\text { burned Area }\end{array}$ & $\begin{array}{c}\text { Recall of Unburned } \\
\text { Area }\end{array}$ \\
\hline $\mathbf{5}$ & 98.2 & 0.134 & 0.99 & 0.98 & 0.98 & 0.99 \\
\hline $\mathbf{1 0}$ & 99.1 & 0.094 & 0.99 & 0.98 & 0.98 & 0.99 \\
\hline $\mathbf{2 0}$ & 99.3 & 0.077 & 0.99 & 0.99 & 0.99 & 0.99 \\
\hline
\end{tabular}

\section{DNN Classifier}

The accuracy derived from an imbalanced and a balanced dataset in a various number of layer is shown in Figure 6. The accuracy is ranging from 95.5-95.7 \% for an imbalanced dataset and $98.5-98.8 \%$ for a balanced dataset. The result shows that the proportion of dataset for burned and unburned area pixels give an impact for the accuracy although still can achieve high accuracy for both imbalanced and balanced dataset.

Table 17 and Table 18 shows the precision and recall values of DNN classifier for an imbalanced and a balanced dataset respectively. From this result, the overall precision of imbalanced dataset is ranging from 0.83- 0.88 , whereas the range for a balanced dataset is $0.97-0.98$. It indicates that the proportion of dataset influences precision value. However, the recall value is not relatively influenced by the proportion of dataset as seen in Table 17 and Table 18 that the recall value is relatively stable.

Furthermore, the different range of precision values and recall values for a balanced dataset and an imbalanced dataset in DNN classifiers are respectively 0.97-0.98; $0.83-0.88$ and $0.93-1.00 ; 0.90-0.99$. Even tough, the high accuracy is still can be achieved in DNN classifier, there is a changing accuracy from $98.5-98.8 \%$ in a balanced dataset to $95.5-95.7 \%$ in an imbalanced dataset.

Table 17: The relationship among number of hidden layer and precision, as well as recall of DN classifier with an imbalanced dataset

\begin{tabular}{|c|c|c|c|}
\hline $\begin{array}{c}\text { Number of } \\
\text { layer }\end{array}$ & Accuracy & Precision & Recall \\
\hline $\mathbf{2}$ & 95.5 & 0.83 & 0.99 \\
\hline $\mathbf{3}$ & 95.7 & 0.88 & 0.92 \\
\hline $\mathbf{5}$ & 95.5 & 0.84 & 0.90 \\
\hline
\end{tabular}

Table 18: The relationship among number of hidden layer and precision, as well as recall of DNN classifier with a balanced dataset

\begin{tabular}{|c|c|c|c|}
\hline $\begin{array}{c}\text { Number of } \\
\text { layer }\end{array}$ & Accuracy & Precision & Recall \\
\hline $\mathbf{2}$ & 98.8 & 0.97 & 1.00 \\
\hline $\mathbf{3}$ & 98.7 & 0.97 & 1.00 \\
\hline $\mathbf{5}$ & 98.5 & 0.98 & 0.93 \\
\hline
\end{tabular}

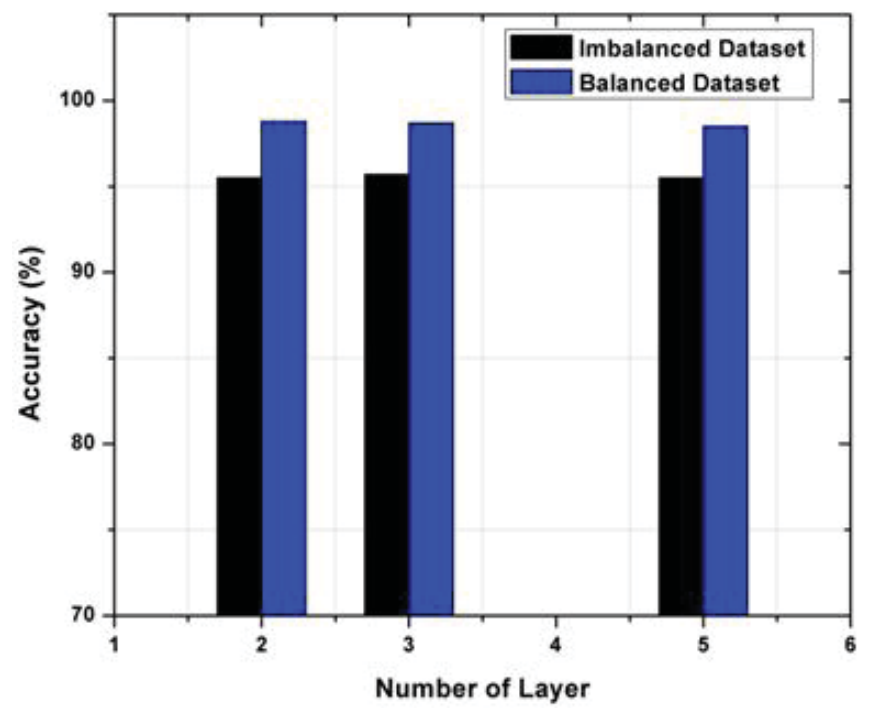

Figure 6: Accuracy between an imbalanced and a balanced dataset on DNN classifier

\section{CONCLUSIONS}

It can be concluded that SVM RBF, RF, and DNN are promising methods to classify the burned area. However, imbalanced dataset affects several classifiers. Based on the study, the imbalanced dataset influences precision and recall value, as well as the accuracy of SVM and DNN classifiers, so that RF outperforms SVM and DNN classifiers in the case of precision values, recall values, and accuracy since RF is relatively not experiencing significant changes on those values in both an imbalanced or balanced dataset.It is shown by the stable range of precision value, recall value, and accuracy for both a balanced dataset and an imbalanced dataset in RF classifier are respectively 0.96-0.99; 0.98-0.99; and $98.2-99.3 \%$. This result also shows that the number of tree does not influence the accuracy in RF classifier. In SVM classifier, the precision and recall values are mostly influenced by the proportion of dataset. Then, the highest accuracy of SVM classifier is derived from the high value of $C$ and the low value of $y$ which ranging from $94.7-98.1 \%$ for an imbalanced dataset and $90.4 \%-98.2 \%$ for a balanced dataset. Furthermore, the different range of precision values and recall values obtained in DNN classifier are respectively $0.97-0.98 ; 0.93-1.00$ for a balanced dataset and $0.83-0.88$; 0.90-0.99 for an imbalanced dataset. Although the high accuracy is still can be achieved in DNN classifier, there is a changing accuracy from 98.5-98.8 \% in a balanced dataset to $95.5-95.7 \%$ in an imbalanced 
dataset. Deep learning will give significant result in a balanced dataset and with a large number of training samples. Also, it gives valuable result in several applications such as image classification so that future work will be focused on the use of a balanced dataset in several deep learning methods. One of the methods is a generative adversarial network which has a promising result for a small amount of training sample.

\section{ACKNOWLEDGEMENT}

This research is funded by Universitas Indonesia under the PITQQ Grant number NKB-00321/UN2.R3.1/ HKP.05.00/2019. Also, the authors thank the Disaster Division, Remote Sensing Application Center - Indonesian National Institute of Aeronautics and Space for giving valuable advice to this research.

\section{REFERENCES}

1. Parwati, S., Zubaidah, A., Vetrita, Y., Yulianto, F., Sukowati, K. A. D., Khomarudin, M. R. (2012). Kapasitas indeks lahan terbakar normalized burn ratio (NBR) dan normalized difference vegetation index (NDVI) dalam mengidentifikasi bekas lahan terbakar berdasarkan data SPOT-4. Jurnal IImiah Geomatika, vol.18, 29-41

2. Suwarsono., Rokhmatuloh., Waryono, T. (2013). Pengembangan model identifikasi daerah bekas kebakaran hutan dan lahan (burned area) menggunakan citra MODIS di Kalimantan. Jurnal Penginderaan Jauh, vol.10, 93-112

3. Zubaidah, A., Vetrita, Y., Khomarudin, M. R. (2014). Validasi hotspot MODIS di wilayah sumatera dan kalimantan berdasarkan data penginderaan jauh SPOT-4 tahun 2012. Jurnal Penginderaan Jauh vol. 11, 1-15

4. The World Bank. (2016). Laporan pengetahuan lanskap berkelanjutan Indonesia: Kerugian dari kebakaran hutan. Jakarta

5. Ministry of Environment and Forestry Republic of Indonesia. Rekapitulasi luas kebakaran hutan dan lahan (Ha) per provinsi di Indonesia tahun 2014-2019, from: http://sipongi.menlhk.go.id/hotspot/luas_kebakaran, accessed 2019-11-01

6. Pinem, T. (2016). Kebakaran hutan dan lahan gambut: kajian teologi ekofeminisme. Gema Teologi, vol.1, no. 2,139-166

7. Yulianti, N. (2018) Pengenalan bencana kebakaran dan kabut asap lintas batas, 1st ed., IPB Press: Bogor

8. Chuvieco, E., Mouillot, F., van der Werf, G. R., San Miguel, J., Tanasse, M., Koutsias, N., García, M., Yebra, M., Padilla, M., Gitas, I., Heil, A., Hawbaker, T. J., Giglio, L. (2019). Historical background and current developments for mapping burned area from satellite Earth observation. Remote Sensing of Environment, vol.225, 45-64, DOI: 10.1016/j.rse.2019.02.013
9. Fanin, T., Van Der Werf, G.R. (2015). Relationships between burned area, forest cover loss, and land cover change in the Brazilian Amazon based on satellite data. Biogeosciences, vol. 12, no.20, 6033-6043, DOI: 10.5194/bg-12-6033-2015

10. Chuvieco, E., Lizundia-Loiola, J., Pettinari, M.L., Ramo, R., Padilla, M., Tansey, K., Mouillot, F., Laurent, P., Storm, T., Heil, A., Plummer, S. (2018). Generation and analysis of a new global burned area product based on MODIS $250 \mathrm{~m}$ reflectance bands and thermal anomalies. Earth System Science Data, vol.10, 2015-2031, DOI: 10.5194/essd-2018-46

11. Langford, Z. L., Kumar, J., Hoffman, M.F. (2018). Wildfire mapping in interior alaska using deep neural networks on imbalanced datasets. 2018 IEEE International Conference on Data Mining Workshops (ICDMW)

12. Mallinis, G., Koutsias, N. (2012). Comparing ten classification methods for burned area mapping in a Mediterranean environment using Landsat TM satellite data. International Journal of Remote Sensing, vol.33, no.14, 4408-4433, DOI: 10.1080/01431161.2011.648284

13. Bastarrika, A., Alvarado, M., Artano, K., Martinez, M. P., Mesanza, A., Torre, L., Ramo, R., Chuvieco, E. (2014) BAMS: a tool for supervised burned area mapping using landsat data. Remote Sensing, vol.6, no. 12, 12360-12380, DOI: 10.3390/rs61212360

14. Roy, D. P., Huang, H., Boschetti, L., Giglio, L., Yan, L., Zhang, H. H., Li, Z. (2019). Landsat-8 and Sentinel-2 burned area mapping - a combined sensor multi-temporal change detection approach. Remote Sensing of Environment, vol. 231, DOI: 10.1016/j.rse.2019.111254

15. Verhegghen, A., Eva, H., Ceccherini, G., Achard, F., Gond, V., Gourlet-Fleury, S., Cerutti, P.O. (2016) The potential of sentinel satellites for burnt area mapping and monitoring in the Congo Basin forests. Remote Sensing, vol.8, no.12, DOI: 10.3390/rs8120986

16. Amos, C., Petropoulos, G. P., Ferentinos, K.P. (2019). Determining the use of Sentinel-2A MSI for wildfire burning \& severity detection. International Journal of Remote Sensing, vol.40, no. 7, 905-930, no. 3, DOI:10.1080/01431161.2018.1519284

17. Filipponi, F. (2018). BAIS2: burned area index for Sentinel-2. Proceedings, vol. 2, DOI: 10.3390/ecrs-2-05177

18. Filipponi, F. (2019). Exploitation of Sentinel-2 time series to map burned areas at the national level: a case study on the 2017 Italy wildfires. Remote Sensing, vol.11, no. 6, DOI: 10.3390/rs11060622

19. Roteta, E., Bastarrika, A., Padilla, M., Storm, T., Chuvieco, E. (2019). Development of a Sentinel-2 burned area algorithm: Generation of a small fire database for sub-Saharan Africa. Remote Sensing of Environment, vol. 222, 1-17, DOI: 10.1016/j.rse.2018.12.011 
20. Jozdani, S. E., Johnson, B. A., Chen, D. (2019). Comparing deep neural networks, ensemble classifiers, and support vector machine algorithms for object-based urban land use/land cover classification. Remote Sensing, vol. 11, no. 14, DOI: $10.3390 /$ rs11141713

21. Noi, P. T., Kappas, M. (2018). Comparison of random forest, k-nearest neighbor, and support vector machine classifiers for land cover classification using sentinel-2 imagery. Sensors, vol. 18, no. 1, 10.3390/ s18010018.

22. Maxwell, A. E., Warner, T. A., Fang, F. (2018). Implementation of machine-learning classification in remote sensing: an applied review. International Journal of Remote Sensing, vol. 39, no. 9, 2784-2817, DOI: $10.1080 / 01431161.2018 .1433343$

23. Zhu, X. X., Tuia, D., Mou, L., Xia, G. S., Zhang, L., Xu, F., Fraundorfer, F. (2017). IEEE Geoscience and Remote Sensing Magazine. October 2017, p. 1-60, DOI: 10.1109/MGRS.2017.2762307

24. Zhang, X., Chen, G., Wang, W., Wang, Q., Dai, F. (2017). Object-based land-cover supervised classification for very-high-resolution UAV images using stacked denoising autoencoders. IEEE Journal of Selected Topics in Applied Earth Observations and Remote Sensing,vol. 10, no. 7, 3373-3385, DOI: 10.1109/JSTARS.2017.2672736

25. Pereira, A. A., Pereira, J.M. C., Libonati, R., Oom, D., Setzer, A.W., Morelli, F., Machado-Silva, F., de Carvalho, L.M.T. (2017). Burned area mapping in the Brazilian savanna using a one-class support vector machine trained by active fires. Remote Sensing, vol. 9, no. 11, DOI: 10.3390/rs9111161

26. Ramo, R., Chuvieco, E. (2017). Developing a random forest algorithm for MODIS global burned area classification. Remote Sensing, vol.9, no. 11, DOI: 10.3390/rs9111193
27. Ramo, R., Garcia, M., Rodríguez, D., Chuvieco, E. (2018). A data mining approach for global burned area mapping. International Journal of Applied Earth Observation and Geoinformation, vol.73, 39-51, DOI: 10.1016/j.jag.2018.05.027

28. de Carvalho, N. S., Ferreira, I.J. M., Korting, T. S., Eduardo, L., Aragao, C.D., Anderson, L.O. (2018). Random forest and support vector machine applied for mapping burned areas in Amazon. Proceedings of XIX Brazilian Symposium on Remote Sensing p. 2833-2836, ISBN: 978-85-17-00097-3

29. Mallinis, G., Mitsopoulos, I., Chrysafi, I. (2018). Evaluating and comparing Sentinel $2 \mathrm{~A}$ and Landsat-8 operational land imager (OLI) spectral indices for estimating fire severity in a mediterranean pine ecosystem of Greece. GI Science\& Remote Sensing, vol. 55, no. 1, 1-18, DOI: 10.1080/15481603.2017.1354803

30. Pepe, M., \& Parente, C. [2018]. Burned area recognition by change detection analysis using images derived from Sentinel-2 satellite: The case study of Sorrento Peninsula, Italy. Journal of Applied Engineering Science, 16(2), 225-232.

31. ESA. (2015). Sentinel-2 user handbook, European Space Agency

32. Lasaponara, R., Tucci, B., Ghermandi, L. (2018). On the use of satellite Sentinel 2 data for automatic mapping of burnt areas and burn severity. Sustainability, vol. 10, no. 11, DOI: 10.3390/su10113889

33. Huang, C., Davis, L.S., Townshend, J.R.G. (2002). An assessment of support vector machines for land cover classification. International Journal of Remote Sensing,vol. 23, no. 4, 725-749, DOI: $10.1080 / 01431160110040323$

Paper submitted: 01.03.2020.

Paper accepted: 24.04.2020.

This is an open access article distributed under the CC BY-NC-ND 4.0 terms and conditions. 